\title{
TESTE DE AGLUTINAÇÃO DIRETA NO SORODIAGNÓSTICO DA LEISHMANIOSE VISCERAL NO ESTADO DO PARÁ
}

\author{
Lourdes M. Garcez, Jeffrey J.Shaw e Fernando T. Silveira
}

\begin{abstract}
Avaliou-seo o teste de aglutinação direta (TAD) no sorodiagnóstico da leishmaniose visceral (2V) humana e de canideos (cão e raposa Cerdocyon thous), sendo os resultados comparados com aqueles obtidos em imunofluorescência indireta (IFI) e ensaio inunoenzimático (ELISA). Utilizaram-se soros: humanos (303): indivíduos com LV confirmada (16), suspeitos de LV (65), em outras condições (102), controles negativos (15), indivíduos em área endêmica (105): de cães (82): de área endêmica (68), Salvaterra/Marajó/PA. (21 parasitologicamente positivos), e controles negativos (14), de Belém; de raposas (9): espécimes capturados na Ilha do Marajo. Antígenos para o TAD foram preparados a partir de promastigotas de Leishmania (Leishmania) donovani $e$ L. (L.) chagasi. Aqueles utilizados em ELISA e IFI, respectivamente, de promastigotas (antígeno solúvel) e amastigotas de L. (L.) chagasi. Em humanos, a especificidade e sensibilidade do TAD, utilizando-se antigeno de L. (L.) donovani, foram altas $(98,4 \%$ e $100 \%$, respectivamente) e comparáveis às de IFI $(97,5 \%$ e $100 \%)$. ELISA foi menos específico $(84,8 \%)$, embora igualmente sensivel. Em câes, o TAD foi mais especifico com antigeno de L. (L.) donovani do que com aquele preparado a partir de L. (L.) chagasi. Entretanto, ELISA e TAD foram menos sensiveis (ambos $71,4 \%$ ) que IFI (100\%). Essa diferença foi refletida nos resultados de cães de área endêmica, $87 \%$ dos quais foram positivos para IFl, mas somente $54 \%$ para ELISA e $49 \%$ para o TAD. Resultados similares foram observados com raposas, quando todos os 9 soros foram positivos para IFI, 7 de $9(78 \%)$ positivos para ELISA, enquanio que o TAD não revelou nenhum resultado positivo. Concluiu-se que o TAD, usando antigeno de L. (L.) donovani é um teste útil para LV humana; sua utilização em ampla escala é indicada, desde que monitorada por um laboratório de referência que garanta qualidade dos antígenos. Contudo, não é a melhor opção em inquéritos sorológicos caninos, já que foi menos especifico que ELISA e, especialmente. IFI. na deteç̧ão de anticorpos em casos de infecção canina.
\end{abstract}

Palavras-chaves: Teste de aglutinação direta. Leishmaniose visceral. Humanos. Canídeos.

A leishmaniose visceral no Estado do Pará, que no início da última década era considerada esporádica, apresenta-se atualmente como um grave problema de saúde pública. Vários focos da doença se estabeleceram em diferentes pontos do Estado, em muitos dos quais caracterizaram-se as atuais endemias.

As dificuldades encontradas no controle da leishmaniose visceral no Estado são de todas as ordens mas, especialmente, de particularimportância no que diz respeito ao diagnóstico dos casos da doença. As áreas de maior transmissão estão a grancles distâncias da capital Belém, onde o Instituto Evandro Chagas é o único laboratório do Estado a realizar testes sorológicos de ELISA e IFI para o

Belém Research Projects e lnstituto Evandro Chagas, Fundação Nacional de Saúde, Ministério da Saúde, Belém, PA.

Endereço para correspondência: Dra. Lourdes M. Garcez.

Recebido para publicação em 08/01/96. sorodiagnóstico da leishmaniose visceral.

Um método de diagnóstico alternativo que pudesse ser utilizado nessas áreas em laboratórios de pequeno porte seria de grande utilidade prática.

Dessa forma, avaliou-se neste estudo a utilização do teste de aglutinação direta, descrito por Harith e $\operatorname{cols}^{10}$, para o sorodiagnóstico da leishmaniose visceral humana e de canídeos (cão e raposa $C$. thous), que constituem os mais importantes hospedeiros de $L$ (L.) chagasi.

O TAD dispensa a utilização de equipamentos sofisticados, é de baixo custo e seus procedimentos são simples de serem executadios. Do ponto de vista técnico, uma das maiores vantagens que apresenta é a de não se utilizar de un conjugado de imunoglobulina espécie-específíco, podendo ser útil em casos de infecções naturais e experimentais de mamíferos da Amazônia. 
Garcez LM, Shaw JJ, Silveira FT. Teste de aglutinação direta no sorodiagnóstico da leishmaniose visceral no Estado do Pará. Revista da Sociedade Brasileira de Medicina Tropical 29:165-180, 1996.

\section{MATERIAIS E MÉTODOS}

\section{Amostras de soro}

Soros humanos: as amostras de soro foram obtidas de indivíduos com leishmaniose visceral comprovada parasitologicamente (9) ou que, submetidos ao tratamento específico, tiveram total regressão dos sintomas (7); controles negativos (15) e portadores de outras infecções parasitárias (102): Ieishmaniose cutânea (20), doença de Chagas (20), malária (32) e esquistosomose (30). Além destas, foram utilizadas 105 amostras de soro de indivíduos assintomáticos residentes em área endêmica (Igarapé Miri/Pará) e outras 65 amostras de soro de indivíduos com sintomas de leismaniose visceral e positivos para IFI, de diferentes localidades do Estado, totalizando 303 amostras.

Soros de cão: as amostras de soro foram obtidas de 68 cães habitantes de área endêmica de leishmaniose visceral (Salvaterra/Ilha do Marajó/ PA), sem sinais aparentes da doença. Destes, 21 $(30,9 \%)$ tiveram a confirmação parasitológica da infecção por Leishmania. Para avaliar a especificidade do TAD foram usadas outras 14 amostras de soro de cães não infectados, aparentemente sadios, procedentes da cidade de Belém, totalizando 82 amostras.

Soros de raposa (Cerdocyon thous): espécimes capturados em área de floresta na Ilha do Marajó, às proximidades do município de Salvaterra, (9).

\section{Diagnóstico parasitológico da infeç̧ão canina}

Realizou-se a pesquisa de Leishmania em cães habitantes do município de Salvaterra/Ilha do Marajó no Estado do Pará. Um total de 68 espécimes sofreu punção medular iliaca e o material foi assepticamente inoculadoem meio Difco B-45 (ágar-sangue). Foram feitas 4 leituras em intervalos regulares de 7 dias para pesquisa de promastigotas. Em casos positivos, realizou-se a identificação das cepas isoladas através de anticorpos monoclonais. Concomitante a tentativa de isolamento em cultura foram ainda preparados esfregaços de medula em lâminas corados pelo Giemsa para pesquisa de amastigotas.

\section{Espécies de Leishmania e cultivo}

Promastigotas de L. (L.) chagasi, L. (L.) donovani cepas MHOM/BR/74/PP75, MHOM/ IN/88/DD8, respectivamente, foram cultivadas em meio RPMI contendo 20mM de HEPES, $10 \%$ de soro bovino fetal e 1\% de GPPS (solução estoque: glutamina $0,2 \mathrm{M}$, ácido pirúvico $0,125 \mathrm{M}$, penicilina/ estreptomicina e 2-ME $50 \mathrm{mM}$ ). Cada cepa cresceu até que predominassem as formas longas do parasita em cultura, de acordo com curva de crescimento previamente estabelecida, para posterior preparo dos antigenos.

\section{Curvas de crescimento}

Promastigotas de cada uma das citadas espécies de Leishmania foram inoculadas em meio RPMISBF 10\%, pH 7,2. O inóculo consistiu de $2 \times 10^{6}$ células concentradas no volume de $1 \mathrm{ml}$, que foi colocado em cada um dos 5 frascos contendo $5 \mathrm{ml} \mathrm{de}$ meio, sendo as culturas incubadas a $26^{\circ} \mathrm{C}$. Diariamente, uma alíquota era tomada de cada frasco e as células contadas em um hemocitômetro. O número de células foi assim determinado com base na média de crescimento nos cinco frascos ${ }^{4}$.

\section{Preparo dos antigenos}

Promastigotas de cada uma das cepas utilizadas neste estudo, cultivadas em RPMI-SBF $10 \%(\mathrm{pH}$ 7,2 ), foram reunidas por centrifugação na fase log e lavadas em PBS ou solução de Locke, de acordo com o antígeno em questão (ELISA ou TAD). Os procedimentos para produção de antígenos foram os seguintes:

TAD. Promastigotas de cultura foram reunidas por centrifugação $(4.000 \mathrm{~g})$ e lavadas 5 vezes por ressuspensão e centrifugação $(3.200 \mathrm{~g})$ em solução de Locke, cuja temperatura era de aproximadamente $4^{\circ} \mathrm{C}$. Após lavagem, uma solução de tripsina $0,4 \%$ diluída em solução de Locke foi preparada, o sedimento foi pesado e acrescentou-se 19 vezes o volume de tripsina correspondente ao seu peso úmido. Os organismos ressuspensos em solução de tripsina foram então submetidos a uma temperatura 
Garcez LM, Shaw JJ, Silveira FT. Teste de aglutinação direta no sorodiagnóstico da leishmaniose visceral no Estado do Pará. Revista da Sociedade Brasileira de Medicina Tropical 29:165-180, 1996.

de $37^{\circ} \mathrm{C}$ durante 45 minutos. Após incubação, os parasitas foram novamente lavados por 5 vezes, como descrito anteriormente, e ressuspensos em solução de Locke a $4^{\circ} \mathrm{C}$ numa concentração de $2 \mathrm{x}$ $10^{8}$ parasitas $/ \mathrm{ml}$. Um volume igual de formaldeído $2 \%$ diluído em solução de Locke a $4^{\circ} \mathrm{C}$ foi adicionado, obtendo-se uma concentração final de $10^{8}$ células $/ \mathrm{ml}$ fixadas em formaldeído a $1 \%$.

Os parasitas foram conservados a $4^{\circ} \mathrm{C}$ por aproximadamente 16 horas (durante à noite), centrifugados $\left(3.200 \mathrm{~g} / 10^{\prime}\right)$ e lavados por ressuspensão e centrifugação $\left(3.200 \mathrm{~g} / 10^{\prime}\right)$ em salina $0,9 \%$ a $4^{\circ} \mathrm{C}$. Em seguida, foram submetidos à coloração pelo corante azul brilhante Coomassie, diluído a $0,02 \%$ em $\mathrm{NaCl} 0,9 \%$ resfriado, com a ajuda de um agitador magnético, durante noventa minutos. Após coloração, foram lavados novamente com $\mathrm{NaCl} 0,9 \%$ resfriado por duas vêzes, como descrito anteriormente e, finalmente, ressuspensos em $10^{8}$ parasitas $/ \mathrm{ml} \mathrm{com} \mathrm{formaldeído} 1 \%$ em salina, o que consistiu o antígeno pronto para uso ${ }^{10}$.

ELISA. Promastigotas foram rompidas a 40 $\mathrm{KHz}$ durante 3 pulsos, de 20 segundos cada, em solução de $\mathrm{NaOH} 0,15 \mathrm{M}(40 \mathrm{ml}$ para $200 \mathrm{mg}$ peso seco). A suspensão foi levada a $4^{\circ} \mathrm{C} / 6 \mathrm{~h}$, sob agitação, lenta para extração das partículas. Em seguida o $\mathrm{pH}$ foi reduzido para 7,2 e a suspensão antigênica levada a $4^{\circ} \mathrm{C}$ durante toda a noite para nova extração, como descrito anteriormente. $O$ antígeno foi centrifugado a $30.000 \mathrm{~g} / 30^{\circ}$ para total remoção de partículas e a dosagem de proteínas realizada de acordo com o método "Waarburg-Christian". Azida sódica foi adicionada ao antígeno, numa concentração de $0,04 \%$, que foi distribuído em alíquotas de $0,5 \mathrm{ml}$ e conservado a $-20^{\circ} \mathrm{C}$ até o momento de uso?

IFI. Amastigotas foram distribuídas em lâminas de IFI pressionando-se fragmento de biópsia de baço, rico em amastigotas, obtido de hamster infectado, sobre os sítios das lâminas com a utilização de uma pinça. Após secagem em temperatura ambiente, foram fixadas por 15 minutos em acetona e estocadas em embalagens plásticas contendo sílica gel a $-20^{\circ} \mathrm{C}$ até o momento de uso ${ }^{21} 22$.

\section{Procedimentos dos testes}

TAD. Soros humanos e de canídeos foram previamente tratados com $0,1 \mathrm{M}$ e $0,2 \mathrm{M}$ de $2-\mathrm{ME}$, respectivamente, e incubados a $37^{\circ} \mathrm{C} / 1 \mathrm{~h}$. Os soros foram diluídos quantitativamente em série de diluições duplas. Soros humanos foram diluídos de 1:100 a 1:102400 e de cães e raposas, 1:40 até 1:10240, exceto quando utilizou-se antígeno de $L$. chagasi (1:40 a 1:2560) Após proceder-se as diluições dos soros em salina fisiológica com SBF $1 \%$, igual volume do antígeno $(50 \mu \mathrm{l})$ foi acrescentado a cada cavidade das placas (cavidades de fundo "V"), que foram mantidas à temperatura ambiente por $18 \mathrm{~h}$. Os testes foram lidos visualmente e o ponto final estimado pela localização de um botão azul, idêntico aquele observado no controle salina/ antígeno $0^{1012} 13$.

ELISA. As concentrações dos antígenos e conjugado para soros de humanos ou de cães foram determinadas pela titulação em bloco, diluindo-se otimamente soros padrões positivos e negativos frente a crescentes concentrações de antígeno e conjugado. O conjugado consistiu de IgG antihumana ou anticão ligada a peroxidase (SIGMA). Dessa forma, utilizou-se 10 e $5 \mu \mathrm{g} / \mathrm{ml}$ de antígeno e diluições dos conjugados de 1:1000 e 1:1500 para humanos e canídeos, respectivamente. Alíquotas de $100 \mu \mathrm{l}$ da suspensão antigênica na concentração adequada, preparada como descrito acima, foram depositadas nas cavidades das placas (cavidades de fundo " $U$ ", da marca Limbro) que foram mantidas a $4^{\circ} \mathrm{C}$ durante a noite (entre 15 e 20 horas) para sensibilização.

As placas sensibilizadas foram lavadas com PBS-tween $0,05 \%$ e o antígeno, adsorvido às cavidades, bloqueado com albumina de soro bovino (BSA) $2,5 \%$ diluída no mesmo tampão $\left(37^{\circ} \mathrm{C} / 1 \mathrm{~h}\right)$. Após lavagem, procedeu-se as diluições duplas em série, de 1:40 a 1:5120, em todos os casos e os soros diluídos foram adicionados e incubados a $37^{\circ} \mathrm{C} / 1 \mathrm{~h}$. Em seguida, as placas foram novamente lavadas e o substrato de orto-fenileno diamino (OPD) foi adicionado na concentração de $2 \mathrm{mg}$ para $10 \mathrm{ml}$ de tampão fosfato-citrato $0,15 \mathrm{M}, \mathrm{pH} 4,5 ; 10 \mu \mathrm{l}$ de 
Garcez. LM, Shaw JJ, Silveira FT. Teste de aglutinação direta no sorodiagnóstico da leishmaniose visceral no Estado do Pará. Revista da Sociedade Brasileira de Medicina Tropical 29:165-180, 1996.

água oxigenada $\left(\mathrm{H}_{2} \mathrm{O}_{2}\right), 30 \%$ foram adicionados para ativação do substrato imediatamente antes do uso. As placas foram incubadas por aproximadamente 30' à temperatura ambiente sob proteção da luz e a reação interrompida com $2,5 \mathrm{M}$ de ácido sulfúrico. Realizou-se a leitura em espectrofotômetro sob comprimento de onda igual a $492 \mathrm{~nm}^{23} 24$.

IFI. As lâminas com antígeno (amastigotas), preparado a partir de $L$. (V.) chagasi, foram lavadas em PBS (20ul em cada sítio contendo antígeno/5') para posterior aplicação dos soros humanos diluídos (diluições duplas: 1/40 a 1/10240). Em seguida, incubadas por $30^{1} / 37^{\circ} \mathrm{C}$, novamente lavadas com jato de PBS para retirar o excesso sendo, posteriormente, imersas em $\mathrm{PBS} / 10^{\circ}$ e água destilada/5'. Após secagem, adicionou-se o conjugado anti-IgG biotinilado diluído otimamente em 1:200 (da marca VECTOR), sendo mantido à temperatura ambiente por 15 a $20^{\prime}$. Excesso de conjugado foi eliminado com jatos de PBS para posterior aplicação da fluoresceína avidina-D (diluída a 1:160 em HEPES 10mM), sucedendo nova incubação como a descrita para o conjugado.

As lâminas foram lavadas com jatos de PBS, secas, montadas com glicerina alcalina sob lamínulas $e$ levadas ao microscópio de fluorescência para leitura ${ }^{21}$.

Em soros de cães e raposas utilizou-se o método convencional de IFI, no qual a anti-Imunoglobulina $G$ está conjugada à moléculas de fluoresceína (da marca SIGMA). Os procedimentos foram idênticos aqueles descritos anteriormente para soros humanos até a adição do conjugado. Neste caso, o conjugado foi diluído em PBS numa proporção de 1:80 e aplicado às amostras de soro durante $30^{\prime} / 37^{\circ} \mathrm{C}$. As lâminas foram lavadas com jato de PBS e imersas em mesmo tampão durante $10^{\prime}$. Após secagem, foram montadas com glicerina alcalina sob lamínulas e levadas ao microscópio de fluorescência para leitura.

\section{Análises estatísticas}

Foram calculados os índices de sensibilidade, especificidade, valores de predição positivos e negativos e índice de concordância para todos os testes na avaliação de soros humanos ${ }^{8}$. Além disso, o teste de significância do Qui-quadrado $\left(\mathrm{X}^{2}\right)$ foi aplicado para determinar eventuais diferenças nos resultados decorrentes da utilização de cada um dos 3 ensaios empregados neste estudo, tanto para soros humanos como para soros de cães.

\section{RESULTADOS}

\section{Padronização dos procedimentos para preparo de antígenos}

\section{Crescimento de Leishmania em RPMI-SBF} $10 \%$. O crescimento de promastigotas de $L$. (L.) donovani e L. (L.) chagasi em meio RPMI-SBF $10 \%(\mathrm{pH} \mathrm{7,2)}$ é demonstrado na Figura 1 . Em todos os casos, o pico de crescimento se deu em torno do $5^{\circ}$ dia, embora observada considerável variação entre as médias deste ponto quando comparadas as duas curvas. A cepa de $L$. (L.) chagasi utilizada

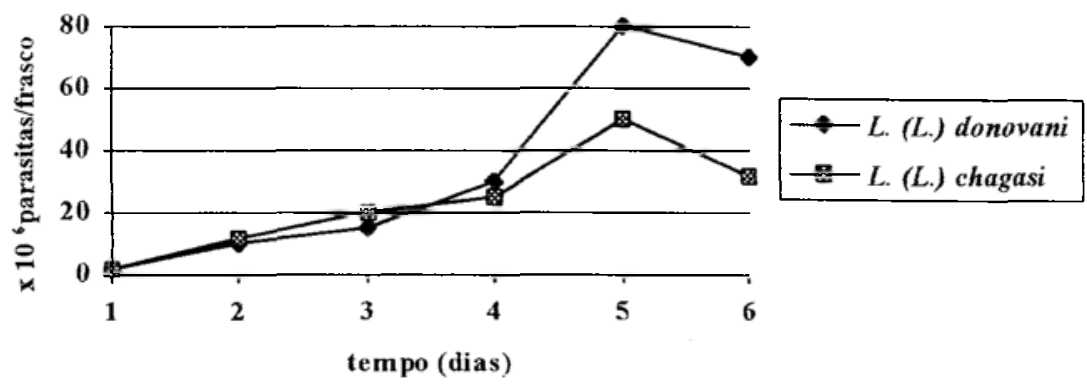

Figura 1 - Crescimento de L. (L.) donovanie L. (L.) chagasi em meio RPMI-SBF 1O\%. Gráfico baseado na média do número de organismos em cinco frascos, cada qual contendo $5 \mathrm{ml}$ de meio. 
Garcez LM, Shaw JJ, Silveira FT. Teste de aglutinação direta no sorodiagnóstico da leishmaniose visceral no Estado do Pará. Revista da Sociedade Brasileira de Medicina Tropical 29:165-180, 1996.

neste estudo revelou-se de difícil desenvolvimento em meio RPMI-SBF 10\%. Entretanto, a movimentação constante da cultura durante o crescimento pôde proporcionar quase duas vezes o número de parasitas esperado em uma cultura estática (Tabela 1). Além disso, um inóculo maior de $10^{6}$ parasitas $/ \mathrm{ml}$ parece ser mais indicado que aqueles utilizados nas curvas de crescimento por proporcionar maior número de organismos.

Tabela 1 - Desenvolvimento de L. R.) chagasi em meio RPMI-SBF 10\% frente a utilizacão de culturas estáticas e sob constante movimento.

\begin{tabular}{cccc}
\hline \multirow{2}{*}{ Inóculo } & \multirow{2}{*}{$\begin{array}{c}\text { Volume de } \\
\text { meio/frasco }\end{array}$} & \multicolumn{2}{c}{ Pico de crescimento } \\
\cline { 3 - 4 } $10^{6} / \mathrm{ml}$ & $250 \mathrm{ml}$ & $6 \times 10^{6} / \mathrm{ml}$ & $10,5 \times 10^{6} / \mathrm{ml}$
\end{tabular}

Padronização de antígenos para o TAD. As dificuldades enfrentadas para a obtenção de antígenos foram principalmente de ordem técnica. Os procedimentos foram executados repetidas vezes e, a princípio, com pouco êxito. Os primeiros lotes produzidos não foram aprovadios, haja vista não ser possível distinguir resultados positivos e negativos. Além disso, em muitas situaçōes, observou-se a presença do "botão de negatividade", contudo, em um formato bizarro, extremamente irregular, o que comprometia sobremaneira a leitura do teste. Após várias tentativas foi possível identificar e solucionar os maiores problemas relacionados a preparação do antígeno para o que diz respeito aos procedimentos de seu preparo. Neste sentido observou-se que:

a) Os procedimentos adotados são rigorosos $\mathrm{e}$ precisam ser repetidos fidedignamente ao preparo de cada lote.

b) Os parasitas a serem utilizados devem ser cultivados em meio líquido (p.e. RPMI-SBF $10 \%$ ), sob o constante movimento do frasco contendo a cultura, favorecendo assim seu crescimento, visto que grande massa de promastigotas é necessária.

c) Os procedimentos exigem que sejam realizadas 10 lavagens das promastigotas em solução de Locke. No entanto, esta solução deve ser mantida a aproximadamente $4^{\circ} \mathrm{C}$ durante todo o processo de lavagem. Se a solução de Locke for utilizada à temperatura ambiente ou superior a $4^{\circ} \mathrm{C}$, embora os parasitas permaneçam vivos, o antígeno não funciona. É também aconselhável utilizar salina resfriada quando a mesma for requerida, maıs tarde, à lavagem dos parasitas.

a) Por ocasião da tripsinização, os parasitas são incubados a $37^{\circ} \mathrm{C} / 45^{\prime}$. Alterações para mais no tempo e temperatura de incubação podem matar a maioria das células, que devem ser mantidas vivas até o momento da fixação.

e) Um forte indicativo de que o antígeno funcionará ao final do processo é a cor da suspensão que deve ter uma tonalidade azul clara.

O primeiro antígeno produzido foi preparado a partir de promastigotas de L. (L.) donovani (MHOM/ IN/80/DD8), espécie original utilizada no trabalho de Harith e cols ${ }^{10}$. A escolha da citada espécie no início de nosso estudo deveu-se também ao fato da mesma apresentar abundante crescimento em meio de cultura (RPMI), se comparado ao crescimento de L. (L.) chagasi.

À primeira instância, o lote de antígeno produzido foi insuficiente para testar quantitativamente todas as amostras de soro humano coletadas. Dessa forma, dadas as dificuldades iniciais encontradas para sua produção, solicitamos um volume de antígeno ao Dr. Harith que nos concedeu gentilmente ( $L$. (L.) donovani, cepa 1-s). Assim, foi possível concluir os resultados referentes a soros humanos, comparando o TAD com IFI e ELISA e calculando sua sensibilidade e especificidade nestes casos, bem como aqueles referentes a soros de cães e raposas.

Em seguida, superadas as dificuldades iniciais, realizou-se a produção de antígenos preparados a partir de $L$. (L.) chagasi, que foi apenas utilizado a título de comparação com antígeno preparado a partir de L. (L.) donovani em soros de cães e de raposas.

\section{TAD para leishmaniose visceral humana}

O TAD com antígeno de $L$. (L.) donovani (1s) revelou $100 \%$ de positividade e altos títulos quando aplicado a soros de indivíduos com leishmaniose visceral americana comprovada parasitologicamente (9) ou em indivíduos sob forte suspeita clínica e epidemiológica quue, após tratamento específico, tiveram total regressão dos sintomas (7). 
Garcez LM, Shaw JJ, Silveira FT. Teste de aglutinação direta no sorodiagnóstico da leishmaniose visceral no Estado do Pará. Revista da Sociedade Brasileira de Medicina Tropical 29:165-180, 1996.

Todos os 15 controles negativos utilizados foram menores ou iguais a 200. Nos soros de doença de Chagas e malária a maioria dos títulos permaneceu abaixo do "cut-off" (igual a 3200) e apenas uma amostra de cada grupo reagiu com título alto ( 6400 e 12800 , respectivamente). Reações positivas não foram observada em indivíduos com leishmaniose cutânea ou esquistosomose como pode ser observado na Tabela 2.

\section{Comparação do TAD com IFI e ELISA no sorodiagnóstico da leishmaniose visceral humana}

Individuos com LVAe sob outras condições. Os três testes foram $100 \%$ sensíveis na detecção de anticorpos em casos de leishmaniose visceral, revelando todos os resultados positivos de 16 amostras de soro testadas, com títulos que variaram de 51200 a $>102400$ no TAD, 2560 a $>10240$ em IFI e 320 a $>5120$ em ELISA (Tabela 3). Os resultados dos testes de IFI e ELISA para soros de pacientes com leishmaniose visceral e indivíduos em outras condições são demonstrados nas Tabelas 4 e 5 , respectivamente.

TAD e IFI foram mais específicos que ELISA $(98,3 \%, 97,5 \%, 84,78 \%$, respectivamente) frente a amostras de soro controle negativas e de indivíduos portadores de outras infecções parasitárias (Tabela 6). Entretanto, esta variação em especificidade deuse em grande parte pela alta freqüência de positividade em ELISA para leishmaniose cutânea (50\%) e doença de Chagas (45\%), enquanto que apenas $6,3 \%$ dos soros de indivíduos portadores malária foram positivos como mostra a Figura 2. Este número indesejável de resultados positivos em ELISA, proporcionado pela sua alta sensibilidade, rendeu um valor de $X_{0,05}^{2}=15,614$, mostrando que diferem significativamente os resultados obtidos em ELISA daqueles obtidos com TAD e, por conseguinte, IFI, utilizando-se as mesmas amostras de soro.

Tabela 2 - Títulos do TAD (antígeno: L. (L.) donovani) para soros de pacientes com leishmaniose visceral e individuos em outras condições, todos provenientes do Estado do Pará.

\begin{tabular}{lcccccccccc}
\hline \multicolumn{10}{c}{$N^{0}$ de amastras e títulos recíprocos } \\
\hline Diag.* & $N^{0}$ & $<200$ & 400 & 800 & 1600 & 3200 & 6400 & 12800 & 51200 & $>102400$ \\
\hline LV & 16 & 0 & 0 & 0 & 0 & 0 & 0 & 0 & 2 & 14 \\
CN & 15 & 15 & 0 & 0 & 0 & 0 & 0 & 0 & 0 & 0 \\
LC & 20 & 9 & 2 & 4 & 3 & 2 & 0 & 0 & 0 & 0 \\
DC & 20 & 7 & 3 & 6 & 1 & 1 & 1 & 0 & 0 & 0 \\
MAL & 32 & 18 & 3 & 4 & 6 & 0 & 0 & 1 & 0 & 0 \\
SCH & 30 & 11 & 7 & 6 & 5 & 1 & 0 & 0 & 0 & 0 \\
\hline Total & 133 & 60 & 15 & 20 & 15 & 5 & 1 & 1 & 2 & 14 \\
\hline
\end{tabular}

* LV: leishmaniose visceral; CN: controle negativo; LC: leishmaniose cutânea; DC: doença de Chagas; MAL: malária; SCH: esquistossomose.

Tabela 3 - ELISA, IFI (antígeno: L. (L.) chagasi) e TAD (antígeno: L. (L.) donovani) para soros de pacientes com leishmaniose visceral comprovada.

\begin{tabular}{lccccccc}
\hline \multicolumn{7}{c}{$\mathrm{N}^{0}$ de amostras e títulos recíprocos } \\
\hline Teste & $N^{0}$ & $<320$ & 640 & 1280 & 2560 & $>5120$ & $>10240$ \\
\hline ELISA & & 1 & 1 & 4 & 3 & 7 & - \\
IFI & $(16)$ & 0 & 0 & 0 & 1 & 0 & 15 \\
TAD & & 0 & 0 & 0 & 0 & 2 & 14 \\
\hline
\end{tabular}

Para o TAD os títulos da tabela são 10 vezes maiores. Ex.: 3200, 6400, 12800 , etc. 
Garcez LM, Shaw JJ, Silveira FT. Teste de aglutinação direta no sorodiagnóstico da leishmaniose visceral no Estado do Pará. Revista da Sociedade Brasileira de Medicina Tropical 29:165-180, 1996.

Tabela 4 - Títulos de 1F1 (antígeno: L. (L.) chagasi) para soros de pacientes com leishmaniose visceral $e$ indivíduos em outras condições.

\begin{tabular}{lcccccccccc}
\hline \multicolumn{10}{c}{$N^{0}$ de amostras e títulos recíprocos } \\
\hline Diag.* & $N^{0}$ & $<40$ & 80 & 160 & 320 & 640 & 1280 & 2560 & $>5120$ & $>10240$ \\
\hline LV & 16 & 0 & 0 & 0 & 0 & 0 & 0 & 1 & 0 & 15 \\
CN & 15 & 15 & 0 & 0 & 0 & 0 & 0 & 0 & 0 & 0 \\
LC & 20 & 19 & 0 & 1 & 0 & 0 & 0 & 0 & 0 & 0 \\
DC & 20 & 18 & 1 & 0 & 1 & 0 & 0 & 0 & 0 & 0 \\
MAL & 32 & 0 & 0 & 0 & 0 & 0 & 0 & 0 & 0 & 0 \\
SCH & 30 & 0 & 0 & 0 & 0 & 0 & 0 & 0 & 0 & 0 \\
\hline Total & 133 & 114 & 1 & 1 & 1 & 0 & 0 & 0 & 0 & 15 \\
\hline
\end{tabular}

* LV: leishmaniose visceral; CN: controle negativo; LC: leishmaniose cutânea; DC: doença de Chagas; MAL: malária; SCH: esquistossomose.

Tabela 5 - Títulos de ELISA (antigeno: L. (L.) chagasi) para soros de pacientes com leishmaniose visceral e indivíduos em outras condições.

\begin{tabular}{lccccccccc}
\hline \multicolumn{7}{c}{$N^{0}$ de amostras e títulos recíprocos } \\
\hline Diag.* & $N^{\circ}$ & $<40$ & 80 & 160 & 320 & 640 & 1280 & 2560 & $>5120$ \\
\hline LV & 16 & 0 & 0 & 0 & 1 & 1 & 4 & 3 & 7 \\
CN & 15 & 15 & 0 & 0 & 0 & 0 & 0 & 0 & 0 \\
LC & 20 & 3 & 4 & 3 & 4 & 2 & 1 & 1 & 2 \\
DC & 20 & 4 & 2 & 5 & 2 & 5 & 2 & 0 & 0 \\
MAL & 32 & 27 & 1 & 0 & 0 & 2 & 0 & 0 & 0 \\
SCH & 30 & 32 & 0 & 0 & 0 & 0 & 0 & 0 & 0 \\
\hline Total & 133 & 81 & 7 & 8 & 7 & 10 & 7 & 4 & 9 \\
\hline
\end{tabular}

* LV: leishmaniose visceral; CN: controle negativo; LC: leishmaniose cutânea; DC: doença de Chagas; MAL: malária; SCH: esquistossomose.

Tabela 6 - Comparação de índices estatísticos calculados na avaliação do TAD, IFI e ELISA para o sorodiagnóstico de leishmaniose visceral humana.

\begin{tabular}{lcccccc}
\hline Teste & Antigeno & Sensibilidade $\%$ & Especificidade $\%$ & $\mathrm{VPP}^{1} \%$ & $\mathrm{VPN}^{2} \%$ & IC $^{3} \%$ \\
\hline ELISA & L. (L.) chagasi & 100 & 98,30 & 88,8 & 100 & 100 \\
IFl & L. (R.) chagasi & 100 & 197,50 & 84,2 & 100 & 100 \\
TAD & L. (L.) donovani & 100 & 84,78 & 43,0 & 100 & 100 \\
\hline
\end{tabular}

$\mathrm{VPP}^{1}$ : valor de predição positivo; $\mathrm{VPN}^{2}$ : valor de predição negativo e $\mathrm{IC}^{3}$ : índice de concordância.

Quanto aos demais índices calculados, apresentados na Tabela 6 , que atestam a validade dos resultados obtidos, constatou-se que os valores de predição positivos do TAD e IFI foram muito aproximados $(88,8 \%$ e $84,2 \%$, respectivamente) $\mathrm{e}$, para ELISA, este valor esteve bem abaixo daquele observado com a utilização de IFI e TAD (43\%). Os valores de predição negativos foram de $100 \%$ para todos os ensaios e os índices de concordância tiveram valores comparáveis no TAD e IFI $(98,5 \%$ e 97,8\%, respectivamente). O índice deconcordância em ELISA foi aparentemente alto (86\%), todavia, diferiu estatisticamente do mesmo índice calculado para o $\operatorname{TAD}\left(\mathrm{X}_{0,05}^{2}=8,93\right)$.

Individuos sob suspeita clinica de LV. Um número considerável de amostras de soro vindas de diferentes Estados da região Norte, bem como Estados de outras regiões, são recebidas no programa de leishmaniose do Instituto Evandro Chagas. Muitas 
Garcez LM, Shaw JJ, Silveira FT. Teste de aglutinação direta no sorodiagnóstico da leishmaniose visceral no Estado do Pará. Revista da Sociedade Brasileira de Medicina Tropical 29:165-180, 1996.

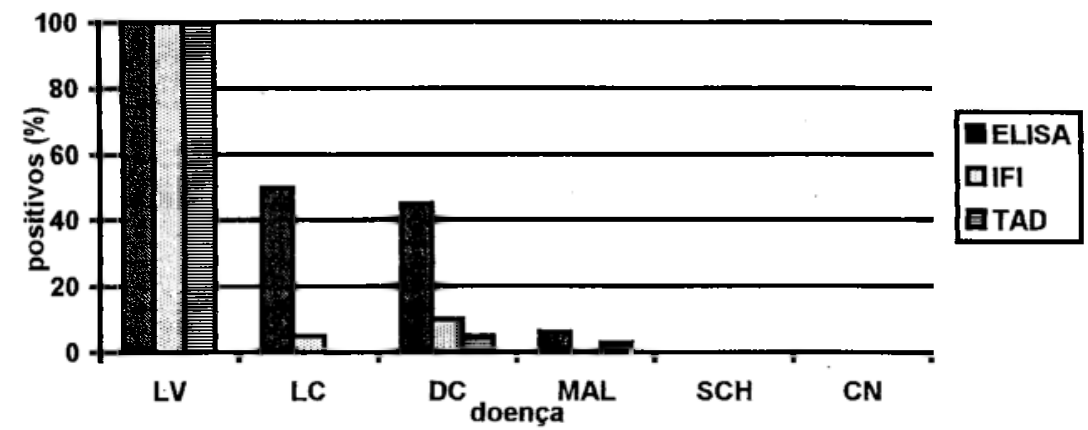

Figura 2 - Freqüencia de positividade para leishmaniose visceral humana utilizandose ELISA, IFI e TAD. Pacientes com LV (16) e individuos em outras condições (117): leishmaniose cutânea (20), doença de Chagas (20), malária (32), esquistossomose (30) e controles negativos (15). Utilizaram-se os seguintes antigenos: L. (L.) chagasi para ELISA e IFI e L. (L.) donovani para o TAD.

delas são tomadas pelo médico com o intuito de avaliar a resposta aos testes imunológicose relacionar com a melhora clínica. Grande número dessas amostras, portanto, não representa o estado imunológico do indivíduo na fase aguda da doença.

Em um grupo de 65 indivíduos, que deram entrada neste laboratório sob suspeita clínica de leishmaniose visceral e foram positivos para o teste de IFI, observou-se:

Os títulos de IFI estiveram entre $2560 \mathrm{e}>$ $10240 \mathrm{em}$ todas as amostras testadas. Observou-se maior semelhança entre os resultados IFI e TAD, uma vez que, para este último, a freqüência de positivos esteve em torno de $93,85 \%$ (títulos de a > 5120 a 102400), quando apenas 4 , de 65 soros, foram negativos para leishmaniose visceral. ELISA revelou apenas $83,08 \%$ de positividade com títulos muito variados $(160$ a $>5120)$, quando 11 , de 65 soros, foram negativos, entretanto, um valor de $\mathrm{X}_{0,05}^{2}=2,712$ demonstra que a diferença entre os resultados de TAD e ELISA não é significativa (Figura 3).

Indivíduos assintomáticos de Igarapé Miri/ Pará. Entre os indivíduos assintomáticos de área endêmica de leishmaniose visceral, ELISA revelou títulos mais baixos que variaram de 320 a $640 \mathrm{em}$ comparação a IFI, cujos títulos estiveram em torno de 160 a 10240 . IFI detectou maior número de resultados positivos $(9 \%)$, se comparado a ELISA (4\%), como se vê na Figura 4. Contudo, um valor de $\mathrm{X}^{2}{ }_{0,05}=1.028$ sugere que a diferença das freqüências de positividade entre os dois testes é insignificante. O TAD não revelou resultados positivos nesta população e o título máximo atingido foi de 800 .

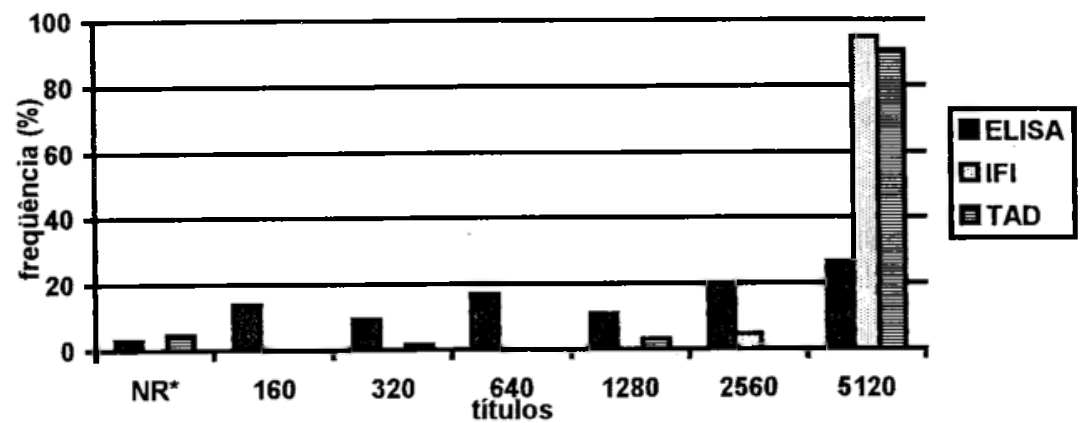

Figura 3 - Anticonpos anti-Leishmania em indivíduos clinicamente suspeitos de LV (65). Para o TAD os tílulos são 10 vezes maiores $(1600,3200,6400$, etc.) Os pontos "cut-off" foram de 1/160, 1/80 e 1/3200 para ELISA, IFI e TAD, respectivamente. NR*. não reativos. 
Garcez LM, Shaw JJ, Silveira FT. Teste de aglutinação direta no sorodiagnóstico da leishmaniose visceral no Estado do Pará. Revista da Sociedade Brasileira de Medicina Tropical 29:165-180, 1996.

ELISA

$100 \%$

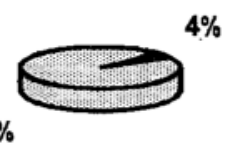

positivos Dnegativos
IFI

TAD

$91 \%$

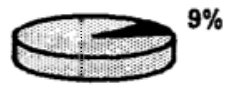

positivos Enegativos

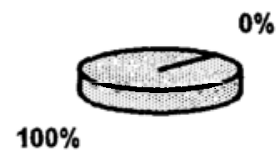

positivos Enegativos

Figura 4 - Sorodiagnóstico de leishmaniose visceral humana em Igarapé Miri/PA. Individuos assintomáticos de área endêmica (105).

Avaliação do TAD para o sorodiagnóstico de leishmaniose visceral canina

Deteç̧ão de anticorpos através do TAD: comparação de dois antígenos. Comparou-se a eficácia do TAD com a utilização de dois diferentes antígenos preparados, respectivamente, a partir de $L$. (L.) donovani e $L$. (L.) chagasi. De acordo com outros autores ${ }^{1319}$, o TAD apresenta especificidade satisfatória quando aplicado a amostras de soros controle negativos (cães de área não endêmica). No entanto, constatou-se neste estudo que o perfil sorológico de cães de área não endêmica foi diferente daquele observado até o momento. De 14 animais da cidade de Belém, apenas $10(71,43 \%)$ apresentaram títulos < 320 e os 4 restantes $(28,6 \%)$ tiveram títulos iguais a $640 \mathrm{com}$ antígeno de $L$. (L.) donovani. Com antígeno de $L$. (L.) chagasi os valores foram ainda mais altos, quando 9 cães $(64,29 \%)$ apresentaram títulos $<320$ e os demais $(35,71 \%)>1280$.

Dessa forma, temos que 5 espécimes, entre os controles negativos, apresentaram títulos muito altos quando a fonte de antígeno para o TAD era $L$. (L.) chagasi e não tão altos quando tratava-se de $L$. (L.) donovani (Tabela 7). Embora os títulos observados com este último estejam também sensivelmente elevados, ainda são mais aceitáveis em casos de animais não infectados, ficando o "cutoff" em torno de 640. Um outro aspecto que favorece a utilização do antígeno de $L$. (L.) donovani é o fato da mesma espécie apresentar abundante crescimento em cultura, tornando muito mais fácil e menos dispendiosa a produção em massa de seu antígeno.

Com relação aos 68 cães de área endêmica (Salvaterra/PA), a Figura 5 demonstra que os títulos observados com a utilização dos dois antígenos são muito próximos e, em geral, comparáveis, especialmente à medida em que tornam-se mais altos (a partir de 320), todavia, optou-se pela a utilização do antígeno não homólogo, haja vista menor reatividade em se tratando de cães não infectados por Leishmania provenientes da cidade de Belém.

Comparação do TAD com IFI, ELISA no sorodiagnóstico de leishmaniose visceral camina. Nas amostras de soro de cães jovens da cidade de Belém, utilizados como controles negativos (14), os títulos do TAD com antígeno de L. (L.) donovani foram $<640$. Em IFI, todas as amostras foram

Tabela 7 - TAD em soros de cães provenientes de área não endêmica (Belém): comparaçäo de dos antigenos de L. (L.) donovani e L. (L.) chagasi.

\begin{tabular}{|c|c|c|c|c|c|c|c|c|c|}
\hline \multicolumn{10}{|c|}{$N^{\circ}$ de amostras e títulos recíprocos } \\
\hline Antígeno & $\mathrm{N}^{0}$ de soros & $<40$ & 40 & 80 & 160 & 320 & 640 & 1280 & $>2560$ \\
\hline L. (L.) donovani & (14) & 0 & 2 & 3 & 2 & 3 & 4 & 0 & 0 \\
\hline L. (L.) chagasi & & 2 & 1 & 0 & 2 & 4 & 0 & 2 & 3 \\
\hline
\end{tabular}




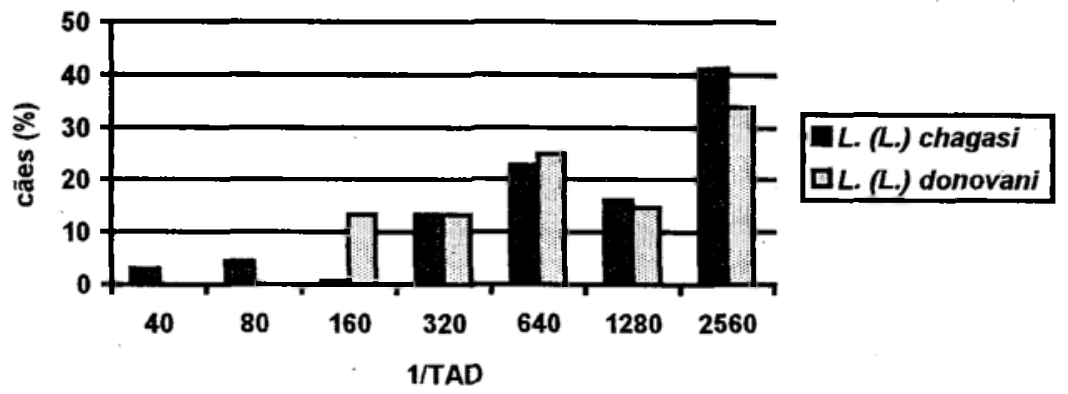

Figura 5 - Sorodiagnóstico de leishmaniose visceral canina: comparação de dois antígenos para o TAD. Um total de 68 amostras de cães habitantes de área endêmica (Salvaterra/Illha do Marajó/PA) foram testadas frente a antigenos de L. (L.) chagasi $e$ L. (L.) donovani.

completamente negativas em 40. Em ELISA, apenas duas $(14,3 \%)$ reagiram em 40 , sendo as demais negativas. Reações positivas foram consideradas a partir de 40 e 80 em IFI e ELISA, respectivamente (Tabela 8).

Em cães de área endêmica sem sinais de doença, o TAD revelou $49 \%$ de positivos com antígeno de L. (L.) donovani, resultado que se aproximou aquele observado em ELISA com antígeno de $L$. (L.) chagasi ( $54 \%$ ). Utilizando-se IFI, com antígeno homólogo, a porcentagem de individuos positivos para leishmaniose visceral foi mais alta, igual a $87 \%$ (Figura 6).

Em cada um dos 68 espécimes utilizados, realizou-se punção medular ilíaca, sendo o material destinado a preparação de lâminas coradas e inoculação em meio de cultura Difco B-45 (ágarsangue) para pesquisa de Leishmania. Este procedimento revelou 21 positivos nesta amostra.

Nestes casos parasitologicamente confirmados a sensibilidade do TAD, com antígeno de $L$. (L.) donovani, esteve em torno de $71,43 \%$, quando 15 indivíduos, dentre 21 , foram positivos. Resultado idêntico foi observado em ELISA com antígeno homólogo (L. (L.) chagasi). IFI com antígeno de $L$.
(L.) chagasi, diferentemente, revelou $100 \%$ de positividade, demonstrando ser o método mais sensível.

TAD, IFI e ELISA para leishmaniose visceral aplicados a um pequeno grupo de raposas $C$. thous. Os nove espécimes capturados em área de floresta, às proximidades do município de Salvaterra, na Ilha do Marajó/Pará, tiveram resultados parasitológicos negativos. A contaminação das culturas foi muito freqüente e as preparações em lâmina a partir de medula óssea não revelaram a presença de amastigotas. Dessa forma, não foi possível utilizar amostras de indivíduos cuja infecção fosse confirmada por meios parasitológicos.

Todas as amostras de soro de raposas foram positivas para IFI, com títulos que variaram de 80 a 1280. ELISA revelou apenas 7 resultados positivos, com títulos a partir 80 até 320 e, com o TAD (L. (L.) donovani), os títulos foram $<640$, demonstrando, portanto $100 \%$ de negatividade. Os pontos de "cutoff" utilizados para soros de raposas foram os mesmos adotados para soros de cães. Utilizou-se também o TAD com antígeno de $L$. chagasi e os resultados estiveram na faixa de 80 a 1280 , no

Tabela 8 - ELISA, IFI (antígeno: L. (L.) chagasi) e TAD (antígeno: L. (L.) donovani) em soros de cães com leishmaniose visceral comprovada.

\begin{tabular}{lcccccccccc}
\hline \multicolumn{1}{c}{$N^{\circ}$ de amostras e títulos recíprocos } \\
\hline Teste & $N^{0}$ de soros & $<40$ & 40 & 80 & 160 & 320 & 640 & 1280 & $>2560$ \\
\hline ELISA & & 2 & 4 & 3 & 5 & 3 & 0 & 1 & 3 \\
IFI & $(21)$ & 0 & 0 & 1 & 1 & 2 & 2 & 15 & - \\
TAD & & 2 & 1 & 0 & 2 & 4 & 0 & 2 & 3 \\
\hline
\end{tabular}




\section{ELISA}

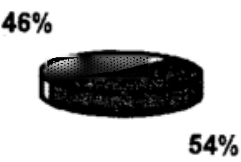

Epositivos Dnegativos
IFI

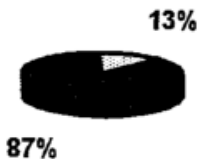

Dositivos Dnegativos
TAD

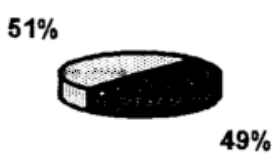

positivos Enegativos

Figura 6 - Sorodiagnóstico de leishmaniose visceral canina em Salvaterra/llha do Marajól Pará. Cães de área endêmica sem sinais de doença (68), entre os quais 30,9\% (21) fora positivos ao exame parasitológico.

entanto, foram considerados negativos, haja vista a observação de títulos ainda mais altos em soros de cães de área não endêmica.

\section{DISCUSSÃO}

A padronização de antígenos e seu controle de qualidade parecem ser dois dos aspectos mais relevantes quanto a utilização do $\mathrm{T} A \mathrm{D}$, uma vezque pequenas variações na técnica de preparo podem comprometer sua eficácia.

Neste estudo, de acordo com os resultados observados, detalhes aparentemente insignificantes, que chegaram a ser negligenciados, revelaram-se a causa do insucesso nos procedimentos na fase inicial do projeto. A título de exemplo, pode ser citada a importância de manter-se a solução de Locke, durante todo o processo de lavagem, a aproximadamente $4^{\circ} \mathrm{C}$, o que exige o constante retorno do frasco, contendo a solução, à geladeira. Normalmente, nas primeiras tentativas de se conseguir o antígeno, este detalhe não foi devidamente valorizado. Corrigindo-se tal procedimento, o sucesso na produção de antígenos foi em média bem maior.

A técnica para o cultivo de parasitas é também de grande importância, pois um número elevado de organismos é requerido ao preparo de antígeno. É indispensável, além do meio de manutenção (ágarsangue), a utilização de um meio de cultura alternativo para produção em massa dos parasitas. São necessários 10 bilhões de parasitas para que se produza $100 \mathrm{ml}$ de antígeno para o TAD, cuja concentração ideal é equivalente a $10^{8}$ parasitas $/ \mathrm{ml}$. No caso de $L$. $($ L.) chagasi, de acordo com sua curva de crescimento, um inóculo de aproximadamente 80 milhões de parasitas $/ \mathrm{ml}\left(8 \times 10^{7} / \mathrm{ml}\right)$ seria requerido em meio RPMI. Quando se utiliza $L$. (L.) donovani, obtém-se aproximadamente o mesmo número de parasitas a partir de um inóculo bem menor $\left(5 \times 10^{7} / \mathrm{ml}\right)$.

Dessa forma, é importante também que procedimentos bem definidos sejam realizados para o cultivo de Leishmania.

Neste estudo, optou-se pela realização de curvas de crescimento com base no trabalho de Celeste e $\mathrm{col}^{4}$ para definição do final da fase loge quantificação de inóculos. A maioria dos autores utiliza promastigotas ao final da fase log para preparar seus antígenos $^{2} 1019$; no entanto, Mengistu e cols ${ }^{17} 18$ referem bons resultados com a utilização de promastigotas na fase estacionária, obtidas entre sete a dez dias após inoculação. Nossos antígenos foram preparados com promastigotas tomadas ao final da fase de crescimento, ocasião em que obtémse o maior número de organismos bem definidos morfologicamente, favorecendo assim a produção de um volume maior de antígeno.

Nossos inóculos corresponderam a números baixos de parasitas $\left(4 \times 10^{6} / \mathrm{ml}\right.$ ou $\left.5 \times 10^{6} / \mathrm{ml}\right)$ se comparados aqueles utilizado por Harith e cols ${ }^{10}$ que, embora não quantificados, sugerem tratar-se de um número muito superior de organismos. A utilização de pequenos inóculos demanda mais gastos na produção de antígeno uma vez que, desta forma, um grande volume de meio será utilizado 
para prover a quantidade desejada.

Acreditamos que os resultados aqui apresentados com respeito a padronização de antígenos para $o$ TAD tenham contribuído para o esclarecimento de importantes aspectos envolvidos nos rigorosos procedimentos da técnica.

A alta sensibilidade e especificidade do TAD. já descritas por outros autores 256101112 , foram confirmadas neste estudo. No tocante à comparação com testes consagrados, constatou-se que o TAD para leishmaniose visceral é capaz de diferenciar soros de indivíduos com doença de Chagas tanto quanto IFI, revelando-se inclusive, um pouco mais específico. Andrade e cols ${ }^{1}$, observaram também que o TAD é capaz de discriminar soros de doença de Chagas utilizando igual antígeno ( $L$. (L.) donovani, cepa 1-s). O teste de ELISA, por sua vez, não distinguiu satisfatoriamente soros de leishmaniose cutânea e doença de Chagas e um número menor de reações positivas foi observado com soros de indivíduos com malária, o que limita o seu uso nas áreas onde estas doenças coexistam com leishmaniose visceral.

É importante ressaltar que IFI vem sendo utilizado para o diagnóstico de leishmaniose visceral no Instituto Evandro Chagas desde a década de 1960 (Shaw \& Voller, 1964), sendo considerada a mais importante ferramenta diagnóstica que se dispõe frente às eventuais dificuldades da realização dodiagnóstico direto. O teste de ELISA, de primeira geração, foi recentemente implantado no Estado pela necessidade que se fez presente, dada a realização deste estudo, todavia, ainda não vem sendo utilizado na rotina diagnósticạ.

Para cada um desses testes, o antígeno teve uma apresentação diferente:

1) Em IFI utilizou-se amastigotas de $L$. (L.) chagasi que, segundo Pappas e cols ${ }^{20}$ e Badaró e cols ${ }^{3}$, promovem especificidade comparável àquela observada com o uso de promastigotas como fonte de antígeno.

2) Uma mistura solúvel de antígenos preparada a partir de promastigotas da mesma espécie para ELISA.

3) Promastigotas intactas de uma espécie causadora de leishmaniose visceral Africana (L. (L.) donovani) como fonte de antígeno para o TAD.

Lemestre e cols ${ }^{16}$ demonstraram que antígenos de superfície de $L$. (L.) donovani e $L$. (L.) chagasi são muito semelhantes. Além disso, Andrade e cols $^{1}$ reportam o reconhecimento destes antígenos de superfície, em níveis similares, por anticorpos aglutinantes humanos.

É importante referir que, no nosso caso, avaliamos a eficácia do TAD comparando com testes consagrados que têm demonstrado um bom desempenho diagnóstico para leishmaniose visceral americana, sendo que este estudo não se deteve a particularidades referentes a diferenças à nível molecular entre determinantes antigênicos atuantes em uma ou outra forma evolutiva do parasita utilizado como fonte de antígeno. A questão é mais voltada para a comparação do TAD com IFI e ELISA para leishmaniose visceral. O resultado desta comparação revelou que um antígeno heterólogo, de $L$. (L.) donovani, pode atuar com desempenho muito satisfatório no TAD e proporcionar bons níveis de especificidade. Dessa forma, $L$. (L.) donovani é indicada como uma boa opção de antígeno no sorodiagnóstico da leishmaniose visceral americana, principalmente pelas facilidades que apresenta sobre o cultivo em relação a $L$. (L.) chagasi. De acordo com Andrade e cols ${ }^{2}$, antígenos preparados a partir dessas duas espécies de Leishmania desenvolvem de forma semelhante na detecção de anticorpos em casos de leishmaniose visceral americana, sendo que $o$ homólogo é responsável por títulos um pouco mais altos.

Embora os resultados de IFI e TAD sejam mais relacionados entre si do que com teste de ELISA, se considerarmos uma amostra da população de indivíduos suspeitos, estes ensaios podem ser igualmente úteis para o diagnóstico, já que grandes diferenças não foram constatadas comparando-se os resultados dos três testes em uma amostra de 65 indivíduos sob forte suspeita clínica de leishmaniose visceral. É bem provável que a freqüência menor de positividade observada em ELISA, nessa amostra, seja decorrente da presença de soros de indivíduos suspeitos que não se encontram na fase aguda da doença. Hailu (1990) ${ }^{9}$ em estudo realizado na 
Etiópia, refere que anticorpos detectáveis emELISA não se mantém por muito tempo, o tratamento específico promove seu declínio progressivo. Refere ainda que o TAD, ao contrário, é capaz de revelar resultados positivos mesmo em pacientes considerados clinicamente curados. Jahn e $\mathrm{col}^{14}$, em estudo realizado no Quênia, não observaram variações significativas nos títulos de soros de pacientes durante o tratamento, que teve um mês de duração. No entanto, após tratamento, os títulos declinaram a níveis observáveis em indivíduos assintomáticos de área endêmica e assim permaneceram de 3 a 12 meses.

Neste estudo, observou-se que o TAD parece. serum teste de grande valor no diagnóstico sorológico da leishmaniose visceral humana, contudo, aparentemente, nãoé sensível o bastante para detectar com freqüência infecções subclínicas ou passadas, já que $100 \%$ dos soros testados de uma amostra de indivíduos assintomáticos de Igarapé Miri/PA ( $\mathrm{n}=$ 105) reagiram muito abaixo do "cut-off". Zijlstra e cols ${ }^{26}$, que relatam alta sensibilidade e valor de predição negativo para o TAD $(94 \%$ e $92 \%$, respectivamente), referem uma freqüência de $5 \%$ de positividade (30 indivíduos) em uma amostra de 600 assintomáticos de área endêmica.

Há que se considerar, no entanto, que se tratam de populações e tamanhos amostrais diferentes, bem como deve ser lembrado um aspecto peculiar a cada população, que é a prevalência da doença. Todavia, vale ressaltar que uma freqüência de positividade em indivíduos de área endêmica foi encontrada quando utilizou-se ELISA e IFI neste estudo, sugerindo que uma parcela dos indivíduos já esteve ou encontra-se infectado por Leishmania na população estudada, o que nos leva a crer que o TAD, de fato, não revela níveis significativos de anticorpos em casos de infecções humanas passadas ou pré-patentes.

Ao contrário do que observou-se com a utilização de soros humanos, o TAD apresentou resultados comparáveis aqueles de ELISA, enquanto IFI (com antígeno de amastigotas), teve um desempenho muito melhor que os demais ensaios em soros de cães parasitologicamente positivos e controles de área não endêmica, revelando-se mais sensível e específico. Estas observações contrariam aquelas feitas por Korte e cols ${ }^{15} \mathrm{em}$ estudo realizado na França, com antígenos de $L$. (L.) infantum e $L$. (L.) donovani, quando demonstrou que os três testes eram comparáveis. No entanto, os autores utilizaram promastigotas como fonte de antígeno, inclusive para IFI. As altas sensibilidade e especificidade do TAD descritas por Harith e cols ${ }^{13}$ e Neogy e cols ${ }^{19}$ não foram observadas na amostra estudada. Em geral a diluição limite ("cut-off") utilizada nestes trabalhos tem sido $1 / 320$. No nosso caso, utilizando-se antígeno de $L$. (L.) donovani, o "cut-off" de 1/640 foi adotado, face às reações observadas em soros de indivíduos não infectados da cidade de Belém.

O desempenho dos três ensaios na amostra de cães de área endêmica, com a infecção comprovada parasitologicamente, sugere novamente que o TAD não é de muita utilidade na deteç̧ão de anticorpos em casos de infecções pré-patentes, além do que, quando o antígeno é preparado a partir de $L$. (L.) chagasi (homólogo, portanto), pode não ser capaz de diferenciar soros positivos e negativos por revelar, nestes últimos, títulos tão altos quanto aqueles detectáveis em casos positivos comprovados.

ELISA, embora tenha apresentado boa especificidade em cães, revelou-se pouco sensivel na detecção de anticorpos em indivíduos parasitologicamente confirmados. A sensibilidade em ELISA foi idêntica aquela observada com o uso do TAD. Os resultados obtidos com IFI revelam uma alta prevalência de anticorpos anti-Leishmania na amostra estudada $(71,43 \%)$. Embora tenha-se detectado uma freqüência bem menor de cães positivos com o uso de ELISA e TAD, os resultados sugerem que esta população canina representa um alto potencial como fonte de infecção humana.

Ainda são necessárias novas investigações no sentido de avaliar o desempenho do TAD frente a soros de cães que apresentem sinais indicativos de doença. Neogy e $\operatorname{cols}^{19}$ relatam que, de 21 cães com leishmaniose visceral confirmada, apenas 1 apresentou resultado negativo tanto no TAD como em "imunoblot". A falta de reatividade sorológica deste cão infectado, com sinais típicos da doença não foi compreendida. 
Garcez LM, Shaw JJ, Silveira FT. Teste de aglutinação direta no sorodiagnóstico da leishmaniose visceral no Estado do Pará. Revista da Sociedade Brasileira de Medicina Tropical 29:165-180, 1996.

Esta primeira avaliação do TAD para leishmaniose visceral canina, no Estado do Pará, sugere apenas que o ensaio não detecta satisfatoriamente anticorpos em individuos comprovadamente infectados, limitando-se, dessa forma, o seu uso em soroepidemiologia, haja vista que dispomos de um teste mais sensível e específico, que é IFI. No entanto, acreditamos que o TAD poderia ser muito útil para esclarecer o diagnóstico em cães que apresentassem sinais da doença.

\section{Conclusões}

O teste de aglutinação direta demonstrou um bom desempenho no sorodiagnóstico da leishmaniose visceral humana, comparável aquele observado em IFI. A sua utilização em ampla escala para o diagnóstico da doença é indicada, desde que monitorada por um laboratório de referência que possa garantir a qualidade dos antígenos utilizados. As observações realizadas neste estudo contribuíram para o entendimento dos procedimentos da técnica e elucidaram aspectos, não descritos por outros autores, relacionados às dificuldades inerentes a produção de antígenos. Um dos pontos mais importantes abordados neste estudo refere-se à utilização do TAD em casos de leishmaniose visceral canina, de grande interesse na epidemiologia da leishmaniose visceral, haja vista o papel deste animal como principal fonte de infecção ao homem. Neste sentido, concluiu-se que o TAD não constitui a melhor alternativa em estudos soroepidemiológicos pois, muito embora apresente as vantagens de ser prático e de baixo custo, não revelou sensibilidade satisfatória, como aquela observada em IFI. No tocante as fontes de antígeno utilizadas, $L$. donovani pareceu ser a espécie mais apropriada para o TAD, por revelar especificidade mais alta que $L$. chagasi frente a soros de indivíduos não infectados. Entretanto novas investigações devem ser feitas no sentido de avaliar este antígeno homólogo utilizandose maior número cães.

Quanto ao TAD em soros de raposas C. thous, o número reduzido de espécimes utilizados e a falta de um diagnóstico parasitológico, que confirmasse a infecção por Leishmania, não permitiu uma avaliação detalhada do desempenho do teste na deteç̧ão de infecção oculta nesse animal. No entanto, os resultados de IFI e ELISA indicam a presença de anticorpos em, pelo menos, 7 dos nove espécimes utilizados. $\mathrm{O}$ fato das mesmas amostras revelaremse negativas para o TAD, adicionado à baixa sensibilidade do teste frente a soros de infecção canina confirmada, sugere que o TAD não seja sensível o bastante para revelar anticorpos em casos de infecção oculta deste canídeo silvestre.

\section{SUMMARY}

The direct agglutination test (DAT) was evaluated for serodiagnosis of visceral leishmaniasis (VL) in human and canids (dogs and foxes Cerdocyon thous). The results were compared with those of the inmunofluorescent antibody assay (IFAT) and enzyme-linked immunosorbent assay (ELISA). The sera used were from: humans (303): confirmed $V L$ (I6), suspected VL (65), other conditions (102), negative controls (15) and individuals from an endemic area (105); dogs (82): from an endemic area (68), Salvaterra/MarajólPará (2I of which were parasitologically positive), and negative controls (14), from Belém; foxes (9): caught on Marajó Island. Antigens for DAT were prepared from promastigots of $\mathrm{L}$. (L.) donovani, L. (L.) chagasi. Antigens used in ELISA and IFAT were prepared from promastigotes (soluble antigen) and amastigotes respectively of $\mathrm{L}$. (L.) chagasi. In humans, the specificity and sensitivity of DAT using $\mathrm{L}$. (L.) donovani were high (98.4\% and $100 \%$ respectively) and comparable to that of IFAT $(97.5 \%$ and $100 \%)$. ELISA was less specific (84.8\%) although similarly sensitive (100\%). In dogs, DAT was more specific using L. (L.) donovani as antigen than using $\mathrm{L}$. (L.) chagasi. However, both DAT and ELISA were less sensitive both $71.4 \%)$ than IFAT (100\%). This difference was reflected in the results from endemic dogs, $87 \%$ of which were positive by IFAT but only $54 \%$ by ELISA and $49 \%$ by $D A T$. Similarly, all 9 fox sera were positive by IFAT, 7 of 9 (78\%) by ELISA but none by DAT. In conclusion, DAT using L. (L.) donovani antigen can provide a useful test for human VL; utilization on a large scale would be possible with a suitable reference laboratory to monitor antigen quality. However, DAT appears less useful for canine studies, as it was less sensitive than ELISA and especially IFAT in detecting canine infection.

key-words: Direct agglutination test. Visceral leishmaniasis. Humans. Canids. 
Garcez LM, Shaw JJ, Silveira FT. Teste de aglutinação direta no sorodiagnóstico da leishmaniose visceral no Estado do Pará. Revista da Sociedade Brasileira de Medicina Tropical 29:165-180, 1996.

\section{AGRADECIMENTOS}

Nossos agradecimentos ao Dr Abdallah El Harith, pelo volume de antígeno gentilmente cedido para a realização de parte desse trabalho, ao $\mathrm{Dr}$ Ralph Lainson pelo constante apoio que nos prestou, esclarecendo muitas dúvidas, e aos Drs Paulo Andrade, Marcelo Barcinski e Alfredo Góes pela revisão crítica do conteúdo. Agradecemos ainda aos Drs Rupert Quinnel e David Courtenay pelo apoio no trabalho de campo.

\section{REFERÊNCIAS BIBLIOGRÁFICAS}

1. Andrade CR, Silva OA, Andrade PP, Kolk AHJ, Harith AE. A direct agglutination test discriminative toward Chagas'desease for serodiagnosis of visceral leishmaniasis in Brazil: preliminary results. Annal Institut Pasteur/ Immunology 138:457-459, 1987.

2. Andrade CR, Nascimento AE, Moura PMMF, Andrade PP. Leishmania donovani donovani e Leishmania donovani chagasi as antigens in the direct agglutination assay for the diagnosis of kala-azar. Brazilian Journal of Medical Biology Research 22:611-615, 1989

3. Badaró R, Reed SG, Carvalho EM. Immunofluorescent antibody teste in American visceral leishmaniasis: sensitivity and especificity of different morfological forms of two Leishmania species. The American Journal of Tropical Medicine and Hygiene 32:480-484, 1983.

4. Celeste BJ, Guimarães MC. Growth curves of Leishmania braziliensis braziliensis promastigotes and surface antigen expression before and after adaptation to Schneider's drosophila medium as assessed by anti-Leishmania human sera. Revista do Instituto de Medicina Tropical de Sào Paulo 30:63-67, 1988.

5. Chowdhury S, Haque F, Al-masum AE, Karim E. Positive response to sodium antimony gluconate administration in visceral leishmaniasis seropositive patients. The American Journal of Tropical Medicine and Hygiene 44:390-393, 1991

6. El Safi SH. Evans DA. A comparison of the direct agglutination test and enzyme-linked immunosorbent assay in the sero-diagnosis of leishmaniasis in the Sudan. Transactions of the Royal Society of Tropical Medicine and Hygiene 83:334-337, 1989.

7. Guimarães MCS, Celeste BJ, Castilho EA, Mineo J, Diniz JMP. Immunoenzimatic assay (ELISA) in mucocutaneous leishmaniasis, kala-azar and Chagas disease. An epimastigote Trypanosoma cruzi antigen able to distinguish between ant i-Trypanosoma and ant $\mathrm{i}$-Leishmania antibodies. The American Journal of Tropical Medicine and Hygiene 30:942-947, 1981

8. Guimarães MCS, Coutinho SG, Antunes CMF. Normas para sorologia de moléstias parasitárias. Revista da
Sociedade Brasileira de Medicina Tropical 20:55-58, 1987.

9. Hailu A. Pre and post-treatment antibody levels in visceral leishmaniasis. Transactions of the Royal Society of Tropical Medicine and Hygiene 84:673-675, 1990.

10. Harith AE, Kolk AH, Kager PA, Leeuwenburg J. Muigai R, Kiugu S, Laarman JJ. A simple and economical direct agglutination test for serodiagnosis and seroepidemiological studies of visceral leishmaniasis. Transactions of the Royal Sociely of Tropical Medicine and Hygiene 80:583-587, 1986.

11. Harith AE, Kolk AH, Kager PA, Leeuwenburg J. Faber FJ, Muigai R, Kiugu S, Laarman JJ. Evaluation of a newly developed direct agglutination test (DAT) for serodiagnosis and sero-epidemiological sludies of visceral leishmaniasis: comparison with IFAT and ELISA. Transactions of the Royal Society of Tropical Medicine and Hygiene 81:603$606,1987$.

12. Harith AE, Kolk AHJ, Leeuewenburg J. Muigai R, Huigen E, Jelsma T, Kager PA. Improvemente of a direct agglutination test for field studies of visceral leishmaniasis. Journal Clinical Microbiology 26:1321-1325, 1988.

13 Harith AE, Splappendel RJ, Reiter 1, Knapen F. Korte P. Huigen E, Kolk AHJ . Application of a direct agglutination test for delection of especific anti-Leishmania antibodies in canine reservior. Journal Clinical Microbiology 27:2252$2257,1989$.

14. Jahn A, Diesfield HJ. Evaluation of a visually read ELISA for serodiagnosis and sero-epidemiological studies of kala-azar in the Beringo District, Kenya. Transactions of the Royal Sociely of Tropical Medicine and Hygiene 77:451-454, 1983 .

15. Korte PM, Harith AE, Dereure J, Huigen E, Faucherre V, Kaay HJ. Introduction of an improved direct agglutination test (DAT) is assessed for the detection of Leishmania infantum infection in southern France. Parasitology Research 76:526-530, 1990.

16. Lemestre JL, Rizvi FS, Afchain D, Sadigursky M, Capron A, Santoro F. Subspecies-specifes surface antigens of promastigotes of the Leishmania donovani complex. Infect. Immunol. 50:136-141, 1985. apud Andrade CR. Silva OA, Andrade PP, Kolk AHJ, Harith AE. A direct agglutination lest diseriminative loward Chagas disease for the diagnoses of visceral leishmaniasis in Brazil: preliminary results. Annal Institut Pasteur/Immunology 138:457-459. 1987.

17. Mengisu G. Kiessling $R$, Akuffo $H$. The value of a direct agglutination test in the diagnoses of cutaneous and visceral leishmaniasis. Transactions of the Royal Society of Tropical Medicine and Hygiene 84:359-362, 1990.

18. Mengistu G, Akuffo H, FehnigerTE, Negese $Y$, Nilsen R. Comparison of parasitological and immunological methods in the diagnosis of leishmaniasis in Ethiopia. Transactions of the Royal Sociely of Tropical Medicine and Hygiene 86:154-157, 1992.

19. Neogy AB, Vouldoukis I, Silva OA. Tselentis Y, Lascombe 
Garcez LM, Shaw JJ, Silveira FT. Teste de aglutinação direta no sorodiagnóstico da leishmaniose visceral no Estado do Pará. Revista da Sociedade Brasileira de Medicina Tropical 29:165-180, 1996.

JC, Thierty S, Rzerpa D, Monjour L. 1992. Serodiagnosis and screening of canine visceral leishmaniasis in a endemic area of Corsica: applicability of a direct agglutination test and immunoblot analysis. The Americ an Joumal of Tropical Medicine and Hygiene 47:772-777, 1992.

20. Pappas MG, McGreevy Hajkowski R, Hendricks LD, Oster CN, Hockmeyer WT. Evaluation of promastigote and amastigote antigens in the indirect fluorescent antibody test for American cutaneous leishmaniasis. The American Journal of Tropical Medicine and Hygiene 32:1260-1267, 1983.

21. Shaw JJ, Ishkawa EAY, Lainson R. A rapid and sensitive method for the identification of Leishmania with monoclonal antibodies using fluorescein-labelled avidin. Transactions of the Royal Society of Tropical Medicine and Hygiene 83:783-784, 1989.

22. Shaw JJ, Lainson R, McMahon PD, David JR. Serodemes of the Leishmania braziliensis complex. Leishmania. Taxonomie et phylogenèse. Applications ècoèpidemiologiques. (Coll. int. CNRS/INSERM, 1984). IMEEE, Montpellier p.179-183, 1986.

23. Voller A, Bartlett A, Bidwell DE. Enzyme immunoassays with especial reference to ELISA techniques. Reprinted from the Journal Clinical Pathology 31:507, 1978.

24. Voller A, Bidwell DE, Bartlett A. Enzyme immunoassay in diagnostic medicine. Bulletin of the World Health Organization 53:55-65, 1976.

26. Zijlstra EE, Siddig Ali M, El-Hassan AM, Eltoum IA, Satti M, Ghalib HW, Kager PA. Direct agglutination test for diagnosis and serological and sero-epidemiological survey of kala-azar in the Sudan. Transactions of the Royal Society of Tropical Medicine and Hygiene 85:474-476, 1991. 